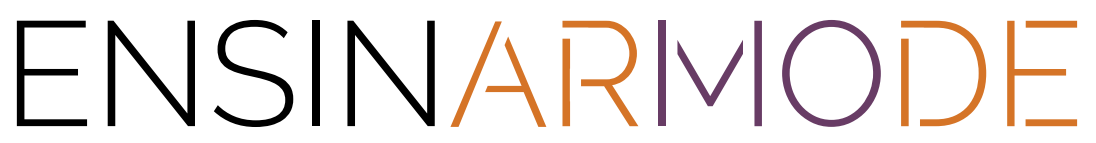

Revista de Ensino em Artes, Moda e Design

Educação e Design Participativo

\title{
O DESIGN PARTICIPATIVO COMO METODOLOGIA DE TRABALHO NA EDUCAÇÃO FORMAL E EM PRÁTICAS COTIDIANAS ${ }^{1}$
}

Participative Design as a Work Methodology in Formal Education and Daily Practices

El Diseño Participativo como Metodología de Trabajo en Educación Formal y Prácticas Diarias

Jaqueline Ferreira Holanda de Melo $^{2}$ 


\section{Resumo}

No presente trabalho, apresenta-se a compilação de uma entrevista realizada por uma docente do Ensino Superior (UFRPE) a uma outra colega de trabalho (Unisinos), a entrevistada que reflete e discute questões relacionadas aos Design Participativo (DP). O caminho da conversa trilhado pelas profissionais abrange não apenas o âmbito educacional, mas o da vida cotidiana, isto é, trata também de como o DP pode ser considerado pragmaticamente para o desenvolvimento e/ou acompanhamento de atividades práticas concernentes e decorrentes de outras dimensões do cotidiano do sujeito social. No percurso de construção do pensamento proposto, termos como curiosidade, proatividade, independência, autonomia e coletividade foram bastante recorrentes para repensar práticas pedagógicas e profissionais que não se restringem ao Design, pois são quesitos necessários a quaisquer atividades em que se intenta que todos que nelas estejam envolvidos participem. No decorrer da entrevista, verificou-se como a adoção das concepções do DP se apresenta como uma prática desafiadora, tanto no campo educacional como na perspectiva de sua atuação em outros campos do saber. Por fim, ressalta-se que, no que concerne aos aspectos técnicos da entrevista, ela foi realizada através da plataforma de vídeo conferência Jitsi Meet, e teve duração aproximada de 40 minutos, gravada via aplicativo de áudio, disponivel para sistema Android - e, na sequência, foi transcrita e organizada de acordo com as normas da língua, tendo sua aprovação para publicação por parte da professora entrevistada.

Palavras-chave: Participação; Pedagogias; Corresponsabilidade.

\section{Abstract}

In the present work, we present the compilation of an interview conducted by a professor of Higher Education (UFRPE) to another co-worker (Unisinos), the interviewee who reflects and discusses issues related to Participatory Design (PD). The path of conversation traced by the professionals covers not only the educational scope but that of everyday life, that is, it also deals with how Participatory Design can be considered pragmatically for the development and / or monitoring of practical activities concerning and arising from other dimensions of everyday life of the social subject. In the course of the construction of thought proposed, terms such as curiosity, proactivity, independence, autonomy, and collectivity were quite recurrent to rethink pedagogical and professional practices that are not restricted to Design, as they are necessary for any activities that intend that everyone who is in them involved par-

${ }^{1}$ Entrevista concedida em 02 de Maio de 2020, via plataforma virtual Jitsi Meet, Recife/PE - Porto Alegre/RS.

${ }^{2}$ Docente na Universidade Federal Rural de Pernambuco no Departamento de Ciências do Consumo, nos cursos de Bach. em Economia Doméstica e Bach. em Ciências do Consumo. Lattes CV: http://lattes.cnpq.br/0639256942534141.ORCID: https:// orcid.org/0000-0001-6929-2759. 
ticipating. During the interview, it was verified how the adoption of the participatory design concepts presents itself as a challenging practice, both in the educational field and in the perspective of its performance in other fields of knowledge. Finally, it should be noted that, about the technical aspects of the interview, it was conducted through the Jitsi Meet video conference platform, and lasted approximately 40 minutes, recorded via an audio application, available for Android system - and, subsequently, it was transcribed and organized according to the norms of the language, having its approval for publication by the interviewed teacher.

Keywords: Participation; Pedagogies; Co-responsibility.

\section{Resumen}

En el presente trabajo, presentamos la compilación de una entrevista realizada por una profesora de Educación Superior (UFRPE) a otra compañera de trabajo (Unisinos), la entrevistada que reflexiona y discute temas relacionados con el Diseño Participativo (DP). El camino de conversación trazado por las profesionales cubre no solo el ámbito educativo, sino también el de la vida cotidiana, es decir, también trata de cómo el Diseño Participativo puede considerarse pragmáticamente para el desarrollo y / o monitoreo de actividades prácticas relacionadas y que surgen de otras dimensiones. La vida cotidiana del sujeto social. En el curso de la construcción del pensamiento propuesto, términos como curiosidad, proactividad, independencia, autonomía y colectividad fueron bastante recurrentes para repensar las prácticas pedagógicas y profesionales que no se limitan al diseño, ya que son necesarias para cualquier actividad que pretenda que todos los que están en ellas involucrado para participar. Durante la entrevista, se verificó cómo la adopción de los conceptos de diseño participativo se presenta como una práctica desafiante, tanto en el campo educativo como en la perspectiva de su desempeño en otros campos del conocimiento. Finalmente, debe tenerse en cuenta que, con respecto a los aspectos técnicos de la entrevista, se realizó a través de la plataforma de videoconferencia Jitsi Meet, y duró aproximadamente 40 minutos, grabada a través de una aplicación de audio, disponible para el sistema Android, y, posteriormente, se transcribió y organizó de acuerdo con las normas del idioma, con la aprobación de la profesora entrevistada para su publicación.

Palabras clave: Participación; Pedagogías; Corresponsabilidad. 


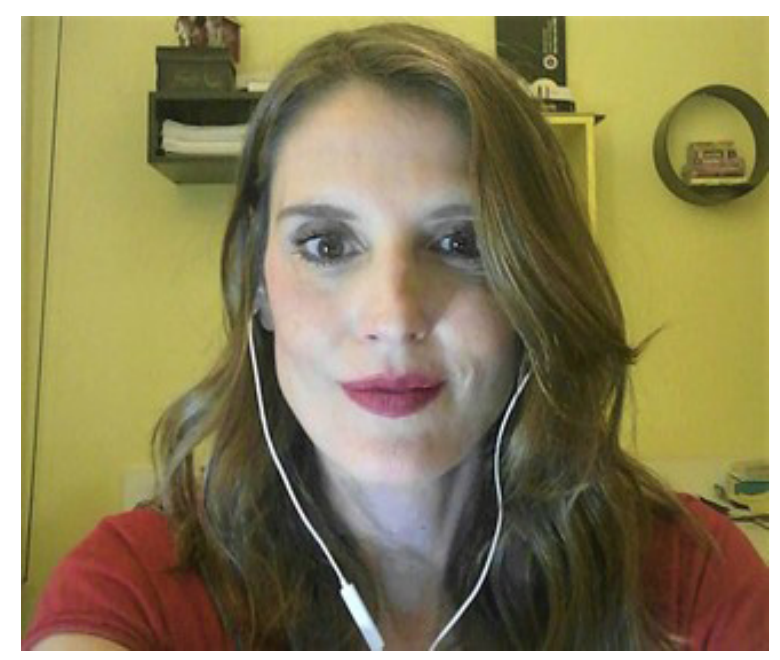

Fotografia 1. Registro Fotográfico da Entrevistada: profa. dra. Paula Cristina Visoná em entrevista concedida em 02 de Maio de 2020, via plataforma Jitsi Meet. Fonte: Acervo da entrevistadora.

Paula Cristina Visoná é doutora em Comunicação Social pela PUC-RS, mestre em Design pela Universidade do Vale dos Sinos (Unisinos) e graduada em Moda e Estilo pela Universidade de Caxias do Sul (UCS). Atua como consultora de empresas, nas áreas de inovação aberta, estratégias de cocriação e pesquisa de tendências e de comportamento de consumo, privilegiando uma abordagem que visa identificar indícios de transformações sociais e culturais para gerar cenários de futuro láreas pertinentes à literatura do Design Participativo]. É coordenadora dos cursos de Especialização em Design Estratégico: Inovação e Prototipagem do Sistema Produto Serviço e da Especialização em Empreendedorismo Criativo, da Escola da Indústria Criativa da Unisinos. Na mesma instituição, é professora dos cursos de Bacharel em Design, Bacharel em Moda e articuladora da Escola da Indústria Criativa, atuando na articulação entre professores e Unidade de Pesquisa de Pós Graduação para a construção de novos projetos de cursos de lato sensu. Fonte: informações cedidas pela entrevistada na plataforma Lattes.

\section{Entrevistador (a):}

A princípio, gostaria que a senhora explicasse didaticamente o que é o Design Participativo? Levando em consideração que ainda é um campo a ser explorado como metodologia educacional ou até mesmo como metodologia de trabalho com grupos e coletividades, em áreas de formação, que não tem aproximação direta com o campo teórico-metodológico do Design.

\section{Entrevistado (a):}

Design é projeto, então o qualificador "participativo" nos faz pressupor um projeto aberto, onde o designer não assume uma figura de gerenciamento, ele não é a figura central: ele 
é um facilitador. Ou seja, no DP a perspectiva é de que as pessoas vão pensar em soluções. No design, o projeto surge de uma demanda muito especíica, uma necessidade, ou algo que se busque ou melhorar ou aprimorar ou mesmo difundir. Então, é possivel pensar em um projeto para a solução de algo, projeto para aprimorar algo, projeto para implementar algo, ou projetos que já sejam baseados em soluções, mas que precisam ser difundidas. É, deste modo, a partir destas situações que se pensa o projeto sob a ótica do DP, em que a ideia é a de que as pessoas pensem por elas mesmas, como elas poderiam atender uma demanda. $O$ designer, via de regra, é uma pessoa que vai agir de modo a facilitar os processos para que as pessoas que estão participando desse momento de criação - "em equipe", em "grupo", em "time" - possam justamente criar em conjunto uma solução. [...]

Então, falando de modo didático, eu diria que o DP é um projeto que pressupõe uma cocriação constante, de modo que as pessoas que participam do processo de criação e também as que posteriormente participam do processo de implementação contribuam com a solução; e o designer, sem dúvida, tem um papel importante, que é o de fazer com que as pessoas reconheçam e valorizem aquilo que estão fazendo como elemento integrante e fundamental de um todo.

\section{Entrevistador (a):}

Especificamente, gostaria que a senhora pudesse tecer considerações sobre o Design Participativo na Educação, seja esta formal ou não-formal. Quais são os caminhos e reflexões possiveis?

\section{Entrevistado (a):}

Penso que a relação mais básica entre o DP e a Educação estaria na própria lógica de projeto. Vamos dizer assim pelas perspectivas até de pedagogias alternativas ${ }^{1}$ ao modelo tradicional de ensino, que visam romper com uma lógica de aprendizado por disciplinas, em "caixas"... No DP, as pessoas vão expressando as suas ideias a partir de um problema ou uma demanda²; e a partir de como as ideias vão se relacionando, a gente vai construindo o projeto, que é algo que pode ser modificado ao longo do tempo... Claro que vai ser colocado em prática aquilo que está sendo construído, mas subentende-se que também não tem um certo ou

\footnotetext{
${ }^{1}$ Sobre a temática "Metodologias Ativas", a entrevistadora recomenda as seguintes leituras: MORÁN, J. Mudando a educação com metodologias ativas. Coleção Midias Contemporâneas. Convergências Midiáticas, Educação e Cidadania: aproximações jovens, v. 2, p. 15-33, 2015.

LOVATO, Fabricio; MICHELOTTI, Angela; LORETO, Elgion. (2018). Metodologias Ativas de Aprendizagem: Uma Breve Revisão. Acta Scientiae. 20. 10.17648/acta.scientiae.v2oisszid369o.

2 Sobre a temática "Aprendizado a partir de Problemas", a entrevistadora recomenda a seguinte leitura: SOUSA, S. O. Aprendizagem baseada em problemas como estratégia para promover a inserção transformadora na sociedade. Acta Scientiarum Education, Maringá, v. 32, n. 2, p. 237-245, 2010.
} 
um errado, ou ainda que não tenha necessariamente um fim, tendo em vista que o princípio orientador é o de que algo sempre pode ser aprimorado. É uma lógica análoga a pensar uma versão beta de algum produto ou serviço, que a gente sempre pode aprimorar, mesmo que o projeto tenha sido compreendido como finalizado, é possível fazer um upgrade. Eu creio que na educação contemporânea, pedagogias que dialoguem com o DP são no sentido de tentar implementar maneiras de promover a educação que não seja baseada no isolamento dos conhecimentos, mas no encontro destes. A pedagogia da transformação ${ }^{3}$ é toda baseada nessa perspectiva, então é uma pedagogia que funciona por projetos; uma pedagogia em que diferentes áreas do conhecimento oferecem exatamente os seus pontos de vista para o projeto, para que este seja construído de modo aberto, para aportar ideias diversas, e a ser

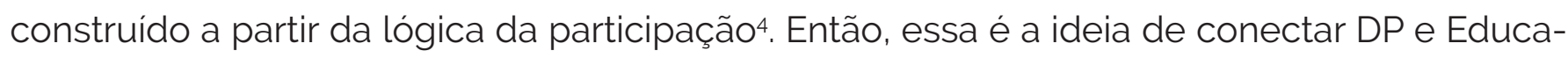
ção. Como colocar isso em prática, seria talvez, justamente, buscando essa perspectiva do designer como facilitador, o professor não seria encarado como o centro de todos os saberes, mas como um facilitador de processos, aprendizagens e conhecimentos. Entendendo, por sua vez, nessa reconfiguração de lógica educacional, que não é o professor que vai dar as respostas, mas as respostas vão ser construidas de maneira colaborativa; então todos, de fato, precisam participar. Tal cenário traz no bojo, subentendido, uma proatividade muito grande por parte dos agentes. Talvez, diante deste elemento tenhamos um desafio a efetivar em um mundo construído muitas vezes a partir de respostas prontas. A proatividade se relaciona à curiosidade - uma pessoa curiosa é potencialmente mais proativa -, e uma mente inquieta, uma mente que não simplesmente aceita aquilo que está sendo colocado como algo que está posto, pronto/acabado e questiona. Eu acredito que essas são características que todos nós temos em maior ou menor grau, e também são competências que podem ser trabalhadas, por diferentes tipos de exercitações. Então, a curiosidade e a proatividade são fundamentais. Não tem como pensar a educação por esta lógica de participação e de colaboração, se não houver proatividade. A pessoa não vai entender algo diferente ou aportar algum conhecimento, se ela não for buscar. Então, em seus aspectos gerais, o DP na Educação propõe uma maneira de educar e de aprender bem mais ativa e bem menos passiva por parte de seus agentes.

\footnotetext{
${ }^{3} \mathrm{~A}$ entrevistadora acredita que coaduna com a perspectiva da entrevistada, fazer menção à temática "Pedagogia da Participação", sobre a qual, recomenda a seguinte obra: NUNES, Débora. Pedagogia da participação: trabalhando com comunidades / Débora Nunes; tradução Ciro Sales; Salvador: UNESCO/ Quarteto, 2002. Disponivel em: <https://cirandas.net/articles/0028/2912/pedagogia_da_participacao.pdf>. ${ }^{4}$ Sobre a temática "Participação", a entrevistadora recomenda a seguinte leitura: GOHN, Maria da Glória. TEORIAS SOBRE A PARTICIPAÇÃO SOCIAL: desafios para a compreensão das desigualdades sociais. Cad. CRH, Salvador, v. 32, n. 85, p. 63-81, 2019 . Available from <http://www.scielo.

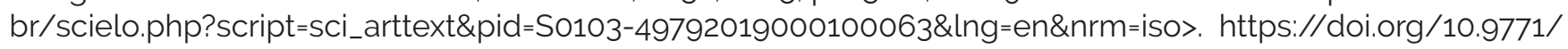
ccrh.v32i85.27655.
} 


\section{Entrevistador (a):}

Tendo em sua atuação como docente no campo do Design, e como coordenadora de uma Especialização voltada para o Design Estratégico, gostaria de saber se a senhora utiliza em sala de aula o design participativo como metodologia de ensino?

\section{Entrevistado (a):}

Sim, me apoio no DP no meu fazer docente. Não necessariamente em todas as disciplinas, não necessariamente com todas as atividades acadêmicas com as quais eu trabalho, algumas mais e outras menos. Em algumas, quando possivel, desde o início do semestre coloco em prática alguns princípios do DP, para que a turma, junto a mim, possa ir construindo, conjuntamente, essas lógicas desse design ao longo da matéria, da disciplina. Há uma unidade curricular com a qual eu trabalho que é chamada de "Pensamento Projetório e Criativo", que é basicamente tudo que dialogamos até agora: o tempo todo eu, na figura de docente, tento trabalhar mais como uma facilitadora do que com uma professora "clássica", que trabalha basicamente com aula expositiva - vamos dizer assim. Tal postura de facilitadora e mediadora do conhecimento trabalho em sala de aula, causa um pouco de estranhamento por parte dos alunos.

\section{Entrevistador (a):}

Diante do uso de elementos do Design Participativo como orientador da sua prática docente, gostaria de saber mais sobre este estranhamento da parte dos (as) estudantes, quando deparam com uma prática em sala de aula que é consideravelmente diferente de uma aula expositiva tradicional, a qual ainda é uma via de trabalho muito frequente no dia a dia do setor educacional.

\section{Entrevistado (a):}

De acordo com as minhas compreensões, este estranhamento se dá não porque eles não estejam preparados, digamos que é algo vinculado não apenas ao sistema de educação, mas a todos os sistemas nos quais nós estamos inseridos, em que se prepara pouco um sujeito para este venha a desenvolver proatividade, independência e autonomia. Então, por mais que isso seja algo que as pessoas queiram - pois elas demonstram almejar autonomia, independência, e trabalhar mais a proatividade etc. -, os nossos sistemas todos não são ainda formatados desta maneira. Talvez, em termos de emprego e trabalho, a proatividade seja hoje mais requerida, pois é uma competência da qual se fala muito, inclusive em entrevistas de emprego - as pessoas de Recursos Humanos falam muito sobre a competência ou ha- 
bilidade da proatividade, mas na educação a gente... [breve pausa reflexiva]. Desde casa, na verdade, a gente é pouco estimulado a essa autonomia e eu acredito que isso se agrava até o momento em que a gente tem um sistema midiático majoritariamente baseado em "receita". Existe uma "cultura do tutorial", o qual pressupõe uma receita; se você seguir um passo a passo, você vai chegar até o resultado de objetivos apresentados; se você fizer tais ações, você vai alcançar tais objetivos... E no momento em que a gente tem a "cultura do tutorial", em certa medida, ela limita a maneira como a pessoa pode atuar de forma proativa, até mesmo porque a proatividade vai além do tutorial; pois uma pessoa até pode se basear em algo que se tem um passo a passo, mas ela vai além daquilo. [entrevistadora: Até mudar o tutorial, concorda?] Sim, até que esta venha a dizer: "Espera um pouco, isso funciona, mas funciona até certo ponto, mas há outra circunstância em que outro elemento não funciona tão bem assim.". Diante de uma ocorrência deste tipo, quem sabe a pessoa se coloca como protagonista e propõe algo diferente? Neste sentido, eu acredito que é importante trabalhar a autonomia desde cedo $^{5}$, há diversas maneiras tentar trabalhar a segurança e autonomia para uma criança, sem fazer com que ela venha se tornar um ser humano dependente. Quanto mais dependentes as pessoas são, menos participativas elas acabam sendo. Situação esta que é relacional, que reflete o não entendimento das pessoas sobre o sentido primeiro da participação, que é a proatividade, a autonomia. Quanto mais as pessoas são proativas, elas serão mais participativas e colaborativas, porque participação e colaboração são ações que se conectam, que tendem à assunção de corresponsabilidade, que está ligada à autonomia, à independência.

\section{Entrevistador (a):}

Considerando que em uma faculdade/universidade existem vários cursos, a senhora vê a possibilidade integrá-los, ou mesmo integrar apenas alguns destes, e utilizar o Design Participativo como metodologia de trabalho?

\section{Entrevistado (a):}

Então, eu vou te dar alguns exemplos que eu mesma já coloquei em prática. Essa é uma prática que na Unisinos, que é a universidade onde eu trabalho, nós tentamos como equipe, por vezes, fazer acontecer. A gente teve ano passado (2019), no primeiro semestre, uma atividade - mais voltada a estudantes de pós-graduação lato sensu e não de graduação, com a presença considerada para o cômputo de carga horária e atribuição de nota ao discente, que viesse a participar. Essa atividade, que é chamada "Atividade Integradora", foi pensada para estudantes que estavam fazendo especialização em Design, ou em Educação, ou em Gestão, ou em Arquitetura, ou na área de Saúde, entre outros cursos da instituição. O planejamen- 
to durou aproximadamente um mês e contou com a participação de um parceiro externo, o qual enviou representantes, que iriam receber suporte para traçar soluções de alguma(s) demanda(s) por eles elencadas a partir das necessidades da organização; de modo que tais soluções seriam propostas pelos(as) estudantes envolvidos(as) na atividade, os quais teriam a oportunidade de interação com uma organização externa ao âmbito acadêmico, de modo que pudessem vislumbrar as possibilidades de aplicação dos conhecimentos estudados em sala de aula.

O parceiro externo, o SICREDI ${ }^{6}$, nos trouxe um problema, na verdade doze problemas. [...] A maioria dos grupos acabou escolhendo o mesmo problema -, que tratava principalmente em "Como desconectar em um mundo tão conectado?". Veja bem: observe como as pessoas ávidas por encontrar uma solução para uma problemática que provavelmente também é importante na vida delas. É evidente que variou a forma como os grupos foram confrontando o problema, como distintos grupos foram trazendo conhecimentos de suas respectivas áreas e aportando soluções para um mesmo problema. Foi um exercício muito importante não apenas para os/as estudantes, mas também para o SIDRED, pois eles saíram com soluções pensadas por 10 grupos diferentes, foi muito rico. A culminância do processo ocorreu em uma manhã. [...] Nós, os professores, participamos como figuras de facilitação, então nós passávamos nos grupos para ver como é que estava o andamento da atividade, quando alguns estudantes ficaram meio "travados", nós auxiliamos um pouco no processo, mas em momento algum qualquer um de nós chegou a dizer: "Você tem que fazer isso aqui" ou "Você tem que fazer aquilo ali". Fomos facilitadores do processo, e claro, os responsáveis por alertar sobre o tempo decorrido: "Vocês tem 'x' tempo, o tempo tá correndo". [...] Para consolidação da atividade, cada equipe de estudantes teve que gravar um vídeo de um minuto apresentando uma solução. Por fim, foi apresentado um feedback para os/as estudantes, não dos(as) professores(as) - a gente se isentou nesse momento -, mas do parceiro externo, o que foi muito válido, pois foi o momento em que o próprio SICREDI, na figura dos colaboradores que estavam ali trabalhando conosco, que expuseram suas impressões, que uma solução era mais alcançável do que outra. Tratou-se de um feedback de olhares externos à academia. Foi um super desafio, mas a atividade funcionou bem. Diante desta experiência, a qual acredito ter sido exitosa, recomendo esse tipo de exercício para que se possa pensar o DP, que é uma abordagem no mínimo interdisciplinar, mas também multi e transdisciplinar. Ou seja, ver um DP como uma metodologia de trabalho, que vise a integração entre cursos é possivel. É desafiador? É, mas funciona.

${ }^{6}$ Cooperativa de Crédito, Poupança e Investimento de Lajeado - Sicredi Integração RS/MG. Fonte: https:// www.sicredi.com.br/html/vale-taquari/sobre/. 


\section{Entrevistador (a):}

Nós estamos dialogando sobre DP voltado para o campo da Educação, de modo que foi possivel perceber que o DP é uma metodologia favorável ao trabalho em grupo, inclusive de sujeitos pertencente a grupos distintos. Sendo assim, considerando uma perspectiva social, gostaria de saber a vossa impressão acerca do DP compreendido como uma metodologia a ser utilizada amplamente na formulação de políticas públicas sociais

\section{Entrevistado (a):}

Penso que seria uma ótima ideia, não sei se, devido à necessidade de se ter autonomia e proatividade, as pessoas estarão preparadas, como já mencionei anteriormente. Mas seria muito bacana, porque, ao invés de alguém ou alguma equipe pensar em como algo pode ser gestado, as próprias pessoas envolvidas no processo é que pensariam como as coisas deveriam ser gestadas e implementadas, quais seriam as soluções para resolver os seus problemas cotidianos, cenário este que teria uma riqueza muito grande. Claro que, com certeza, num primeiro momento, poderia ser gerada muita tensão, porque ideias diferentes podem ser concorrentes, de modo que cada um reivindica para o lado que mais lhe convém, assim seria muito importante ter uma equipe preparada para lidar com o tensionamento de modo a não tendenciar ou priorizar certas soluções em detrimento de outras. Presumir-se-ia pensar nos pontos de contato que surgiriam da diferença entre pontos de vista confrontados. $O$ que representa uma dinâmica de DP não é "se essa ideia é melhor" ou "se aquela é uma ideia melhor", e sim o diálogo que pode existir entre diferentes visões de mundo diante um mesmo problema.

Em relação a uma ampla adoção, não acredito que todo mundo abrace a ideia de trabaIhar pensando na coletividade sob a perspectiva do DP, porque nunca é "todo mundo", nunca algo é homogêneo, e é preciso lidar com heterogeneidade, é necessário lidar o tempo todo com o que é diferente. E o DP pressupõe que essas diferenças e heterogeneidades são importantes, por isso que o projeto nunca está pronto e "fechado", como expliquei anteriormente; por isso também que, pensando numa lógica de futuro, de cenários de futuro, que a partir desse ponto de vista, é possivel acreditar que haja uma ampla adoção do DP no traçado de políticas públicas, sem esquecer que as propostas sempre estarão abertas a interferências. Então, sim, é possivel que nós teremos um futuro de políticas públicas permeado por práticas participativas.

\section{Entrevistador (a)}


Além de vislumbrar o DP como metodologia de trabalho para o traçado de Políticas Públicas, outro assunto vastamente discutido na área social é a vigência da Sociedade de Consumo, assim gostaria de saber por fim: o que a senhora considera a respeito da relação entre DP e Consumo Consciente ${ }^{8}$ ?

\section{Entrevistado (a)}

Considero uma relação totalmente possivel. Não que o Consumo Consciente dependa do DP, mas eu acredito que é uma relação que tende a se efetivar, pois no momento em que as pessoas entendem que elas podem pensar em soluções, para suas demandas, para suas problemáticas; elas se tornam mais conscientes. [...] E como o consumo é parte da nossa vida cotidiana, ele é com certeza um dos âmbitos que pode ser alcançado pelo DP. Contudo, creio que a dita "consciência" se estende para outras lógicas e práticas também, como de sociabilidade, de relação com as pessoas, enfim, em outros âmbitos que fazem parte do nosso dia a dia.

\section{Entrevistador (a):}

Considerações finais: é pertinente registrar que a entrevistada recomendou, ao final da entrevista, a obra: MANZINI, Ezio. Design. Quando Todos Fazem Design. São Leopoldo, RS: Ed. Unisinos, 2017.

A partir da entrevista apresentada, reitera-se que a temática da Participação é imprescindivel para se pensar a Educação e as metodologias do DP são bem-vindas à prática docente, como foi possivel observar na fala da entrevistada, embora a adoção de metodologias participativas em sala de aula ainda cause estranhamento em estudantes, é um caminho possivel. Em suma, esta entrevista resultou em uma oportunidade para refletir sobre a abrangência da aplicação do DP, principalmente na área da Educação, bem como na área social e em processos que repercutem na vida cotidiana, como Políticas Públicas e Consumo Consciente, que são temáticas de interesse da entrevistadora9.

${ }^{8}$ Sobre a temática "Consumo Consciente"a autora recomenda a seguinte obra: PORTILHO, Fátima. Sustentabilidade ambiental, consumo e cidadania. São Paulo: Cortez, [2005] 2010.

${ }^{9}$ Revisor Gramatical: Eduardo Manoel Barros Orácio. Lattes CV: http://lattes.cnpq.br/og28351632540394. 